\title{
Standard Precautions and Infection Control, Medical Students' Knowledge and Behavior at a Saudi University: The Need for Change
}

\author{
Tarek Tawfik Amin ${ }^{1,2}$, Khalid Ibrahim Al Noaim³, Mohammed Ahmed Bu Saad ${ }^{3}$, Turki Ahmed Al Malhm³, \\ Abdullah Abdulaziz Al Mulhim ${ }^{3} \&$ Marwah Abdulaziz Al Awas ${ }^{3}$ \\ ${ }^{1}$ Public Health, Faculty of Medicine, Cairo University, Cairo, Egypt \\ ${ }^{2}$ Family and Community Medicine, College of Medicine, King Faisal University, Hofuf, Saudi Arabia \\ ${ }^{3}$ College of Medicine, King Faisal University, Hofuf, Saudi Arabia \\ Correspondence: Tarek Tawfik Amin, Associate Professor, Community Medicine and Public Health, Faculty of \\ Medicine, Cairo University, Cairo, Egypt. E-mail: amin55@myway.com
}

Received: March 26, 2013 Accepted: April 15, 2013 Online Published: April 21, 2013

doi:10.5539/gjhs.v5n4p114 URL: http://dx.doi.org/10.5539/gjhs.v5n4p114

\begin{abstract}
Background: No previous studies have reported the knowledge of Saudi medical students about Standard Precautions (SPs) and infection control. Objectives: The objectives of this study were to assess medical students' knowledge in clinical years at King Faisal University, Saudi Arabia about SPs' and to explore their attitudes toward the current curricular/training in providing them with effective knowledge and necessary skills with regard to SPs. Subjects and Methods: This cross sectional study targeted students in clinical stage at College of Medicine, King Faisal University, Saudi Arabia. A pre-tested anonymous self administered data collection form was used. Inquires about students' characteristics, general concepts of infection control/SPs, hand hygiene, personal protective equipment, sharp injuries and disposal, and care of health providers were included. The main source of information for each domain was also inquired. The second part dedicated to explore the attitudes toward the curricular and teaching relevant to SPs. Results: A total of 251 students were included. Knowledge scores in all domains were considerably low, 67 (26.7\%) students scored $\geq 24$ (out of 41 points) which was considered as an acceptable level of knowledge, $22.2 \%$ in $4_{\text {th }}$ year, $20.5 \%$ in $5_{\text {th }}$ year and $36.8 \%$ in $6_{\text {th }}$ year. Sharp injuries, personal protective equipment and health care of the providers showed the least knowledge scores. The main sources of knowledge were self learning, and informal bed side practices The majority of students' believed that the current teaching and training are insufficient in providing them with the necessary knowledge and skills regarding SPs. Conclusion: The overall knowledge scores for SPs were low especially in the domains of hand hygiene, sharp management, and personal protective equipment reflecting insufficient and ineffective instructions received by medical students through the current curriculum posing them vulnerable to health facilities related infections. Proper curricular reform and training are required to protect students and their patients.
\end{abstract}

Keywords: standard precautions, infection control, knowledge, medical students, Saudi Arabia

\section{Introduction}

Standard precautions (SPs) are designed to reduce the risk of acquiring occupational infection from both known and unexpected sources in the healthcare setting (Seigel et al., 2007). Strict adherence by health staff (healthcare providers [HCPs] including students) to SPs may prevent a percentage of these risks (Philips \& Ker, 2006). SPs have two objectives namely to protect HCPs from percutaneous injuries and to prevent transmission of nosocomial infection. Due to their limited experience in performing invasive procedures, medical students are at particular risk of exposure to blood-borne pathogens (Jeffe et al., 1907; Wiwanikit, 2002). Medical students should have adequate knowledge before their initial training period at hospital which is a pre-requisite for compliance. Moreover, Elliott et al. reported that specialized training must be received before a health care student undertakes any patient procedure involving sharp devices (Elliot et al., 2005). Physicians' knowledge of SPs has been reported to be insufficient (Sax et al., 2005; Bryce et al., 2007; Easton et al., 2007). Few studies (Askarian et al., 2004; Mann \& Wood 2006; Koeing \& Chu, 1993; Elliot et al., 2005) have reported on medical students' knowledge of SPs or sharp injuries and noted a lack of adequate knowledge of SPs. The observance of hygiene recommendations by students is reported as being weak: medical students rarely wash their hands after examining patients (Feather et al., 2000; Hunt et al., 2005). Poor compliance may have its roots in a failure to learn this simple, essential behavior at 
medical school (Feather et al., 2005). Learning practices are indispensable for improving student knowledge of nosocomial infection (Kim et al., 2001; Calabro et al., 1998) and the prevention of infection transmission (Colombo et al., 2002). In Saudi Arabia, it was reported that there was a lack of knowledge and compliance of infection control measures by health care providers in hospitals as well as at primary level of care (Maqbool, 2002). This was partially explained by the deficiency of the curricular content of medical and nursing schools in Saudi Arabia (Maqbool, 2002) as well as in many other developing countries where the role of SPs and infection control is not emphasized and SPs are often practiced incompletely, with limited understanding and thus suboptimal compliance (Maqbool, 2002; Kermode et al., 2005). Assessing medical students' knowledge towards SPs will aid in prevention of nosocomial infections and can provide the foundations for curricular reform necessary to provide them with adequate knowledge and skills.

Studies form Saudi Arabia that assessed medical students' knowledge towards SPs are scarce. The objectives of this study were to assess medical students' knowledge in clinical years at King Faisal University, Saudi Arabia about SPs' and to explore their attitudes toward the current curricular/training in providing them with effective knowledge and necessary skills with regard to SPs.

\section{Subjects and Methods}

\subsection{Setting and Design}

This was a cross-sectional study carried out at College of Medicine, King Faisal University, Saudi Arabia. The college is running two curricula concurrently, traditional and problem based learning (launched in 2012). The total number of students enrolled (both genders) were 435 in the clinical years $\left(2_{\text {nd }}\right.$ semester of the $4_{\text {th }}, 5_{\text {th }}$ and $6_{\text {th }}$ years) and about 500 in the preclinical stage. The current traditional curriculum has no course (partially or in whole) that is dedicated for orientation/training of medical students in regard infection control and SPs, and relevant information are delivered through scattered lectures in the context of other courses namely microbiology and epidemiology in the preclinical stage.

\subsection{Subjects}

All medical students at the College of Medicine, King Faisal University of both genders at their clinical rotations were invited to participate. Data collection has taken place between April $1_{\text {st }}$ and June $20_{\text {th }}$, year 2012.

\subsection{Data Collection}

Data were collected through a self administered anonymous questionnaire including the following sections:

- Socio-demographics including age, year of study at the college, gender, received previous training or educational materials about infection control and SPs. The average number of patients' the medical students were exposed to in the last 30 days, hand washing frequency following exposure to patients'.

- Knowledge about different domains of infection control and SPs: consisted of closed ended questions in multiple choice or the options of true, false and I do not know format. The used items were adopted from the available literature (Amin \& Al Wehedy, 2009; Tavolacci et al., 2008); the English version of the questionnaire was used as it is the formal teaching language. The questionnaire included quires about the different domains of SPs namely the general concepts of infection control and SPs (5 questions), hand hygiene (10 questions), personal protective equipment (PPE) (9 questions), sharps disposal and injuries (8 questions) and care of health care providers to avoid health care-related infections (9 questions), with a total of 41 items. Correct responses were assigned one score while incorrect /do not know responses assigned nil.

- For each domain of knowledge, the main source for information was inquired whether through the curriculum, self learning, ward practices or formal bed side teaching.

- Inquires exploring the attitudes of medical students towards the role current curriculum and teaching in providing essential training /orientation towards infection control and SPs, whether they are fulfilling their knowledge gap and their need for training in the domain of infection control and SPs were added. Five questions were adopted form the available literature (Humphreys \& Richards, 2011) with Likert scale from strongly disagree to strongly agree.

\subsection{Questionnaire Administration}

Before questionnaire administration, investigators emphasized the right of the student of not to participate and the confidentiality of the process. Investigators conducted an orientation sessions for participants to explain the objectives, terms used in the data collection form and assist them for any difficulty if any.

Pilot testing was carried out on $3_{\text {rd }}$ year students $(n=41)$, reliability analysis (Cronback's alpha) of the final data 
collection form (41 items) was .58 , reliability coefficients for different components were as follow .51 for the general concept, hand hygiene $=.74, \mathrm{PPE}=.80$, sharp injuries and disposal $=.78$, care of the HCPs $=.81$. The attitudes items showed a reliability coefficient of .72 .

\subsection{Data Analysis and Management}

Data entered and analyzed using SPSS version 16.0 (Chicago, Ill, USA). Forms with missing of two or more items were discarded $(n=14)$. Out of the total students invited $(n=435), 265$ responded (response rate of $60.9 \%)$. Fourth year (both genders $n=142)$ showed a response rate of $57.0 \%, 5_{\text {th }}$ year $(n=133) 62.4 \%$, and $6_{\text {th }}$ year $(n=145) 60.0 \%$. Both descriptive and inferential statistical analyses were applied. For categorical variables, proportion and percentage were used for expression, Chi square and $Z$ tests were used for comparison, for numerical variables, median, mean and standard deviation were employed for expression, Mann Whitney and Kruskal Wallis statistical tests were used for comparison. Scores for different domains were reported with a $25_{\text {th }}$ percentile of 16 points (out of 41), $50_{\text {th }}$ percentile of 20 and the $75_{\text {th }}$ percentile ( 24 points); we employed 24 score as a cut off for sufficient knowledge for infection control and SPs. Logistic regression model was generated to determine the possible predictors of acceptable knowledge (dependent variable) against the possible independent variables including gender, year at college, previous receiving of training and teaching/educational materials regarding infection control and SPs and the attitudes scores. P value of $<0.05$ was set as the level of statistical significance.

\section{Results}

\subsection{Basic Characteristics and General Concept of Infection Control and Standard Precautions and Hand Hygiene}

Of the included participants $48.6 \%$ were females, $6.0 \%$ mentioned the receiving of previous training/orientation on infection control and SPs, and $21.5 \%$ had received teaching/educational materials regarding infection control and SPs (Table 1). The contents of the received training/orientation were in the form of half day sessions held at the local secondary level of care hospitals as a part of continuing medical education and composed of lectures and video demonstration of hand hygiene, sharp management and prevention of nosocomial infections.

Table 1 also demonstrates the responses of knowledge items about the general concepts of infection control and SPs, $18.3 \%$ and $51 \%$ did not recognize the goal of infection control and the precise definition of SPs respectively. Only $41.8 \%$ recognized that all patients are sources of infection and only $31.9 \%$ stated that all body fluids except sweat should be viewed as sources of infection. For this domain a total score was $3.1 \pm 1.2$ (out of 5), significantly higher among those at $6_{\text {th }}$ year (Kruskal Wallis, $\mathrm{P}=0.010$ ). Only $39.0 \%$ were able to respond correctly about the standard duration of hand washing, $51.1 \%$ believed that alcohol hand rub can replace hand washing even if the hands were soiled, $33.5 \%$ acknowledged that using gloves replaces the need for hand washing and only $34.3 \%$ correctly stated the need for hand washing in dealing with patients with respiratory infections. For this domain a total knowledge score was $5.8 \pm 2.2$ (out of 10 points), significantly more among those at $6_{\text {th }}$ year $(\mathrm{P}=0.013)$. 
Table 1. Characteristics of the medical students participated in the survey and correct responses about general concepts of infection control-standard precautions and hand hygiene by year of study

\begin{tabular}{|c|c|c|c|c|}
\hline \multirow[b]{2}{*}{ Characteristics } & \multicolumn{4}{|c|}{ Years and Correct answers: No. (\%) } \\
\hline & $\begin{array}{l}\text { Fourth } \\
(\mathrm{N}=\mathbf{8 1})\end{array}$ & $\begin{array}{l}\text { Fifth } \\
(\mathrm{N}=\mathbf{8 3})\end{array}$ & $\begin{array}{l}\text { Sixth } \\
(\mathrm{N}=\mathbf{8 7})\end{array}$ & $\begin{array}{l}\text { Total } \\
(\mathbf{N}=\mathbf{2 5 1})\end{array}$ \\
\hline \multicolumn{5}{|l|}{ Gender } \\
\hline Males & $40(49.4)$ & $43(51.8)$ & $46(52.9)$ & $129(51.4)$ \\
\hline Females & $41(50.6)$ & $40(48.2)$ & $41(47.1)$ & $122(48.6)$ \\
\hline Previous training / orientation on SPs-IC & $6(7.4)$ & $4(4.8)$ & $5(5.7)$ & $15(6.0)$ \\
\hline Received educational materials/instructions about SPs-IC & $21(25.9)$ & $17(20.5)$ & $16(18.4)$ & $54(21.5)$ \\
\hline \multicolumn{5}{|l|}{ General concept of infection control and standard precautions: } \\
\hline 1- The main goal of infection control : Options & $65(80.2)$ & $59(71.1)$ & $81(93.1)$ & 205(81.7) \\
\hline 2- Definition of standard precautions: Options & $33(40.7)$ & $42(50.6)$ & $48(55.1)$ & $123(49.0)$ \\
\hline 3- All patients are sources of infection regardless their diagnoses. True & $33(40.7)$ & $31(37.3)$ & $41(47.1)$ & $105(41.8)$ \\
\hline 4- All body fluids except sweat should be viewed as sources of infection. True & $25(30.9)$ & $18(21.7)$ & $37(42.5)$ & $80(31.9)$ \\
\hline 5- All health providers are at risk of occupational infections. True & $37(45.7)$ & $54(65.1)$ & $78(89.7)$ & $189(75.3)$ \\
\hline Score for general concept (out of 5): Median (mean \pm SD) & $3.0(2.6 \pm 0.9)$ & $3.0(2.5 \pm 1.3)$ & $4.0(3.6 \pm 1.0)$ & $3.0(3.1 \pm 1.2)$ \\
\hline \multicolumn{5}{|l|}{ Hand Hygiene: } \\
\hline 1- Hand washing minimizes microorganisms acquired on the hands if soiled. True & $42(51.9)$ & $59(71.1)$ & $62(71.3)$ & $163(64.9)$ \\
\hline 2- Hand washing reduces the incidence of healthcare-related infections. True & $53(65.4)$ & $61(73.5)$ & $65(74.7)$ & $179(71.3)$ \\
\hline 3- Standard hand washing includes washing of both hands and wrists. True & $53(65.4)$ & $55(66.3)$ & $59(67.8)$ & $167(66.5)$ \\
\hline 4- In standard hand washing: minimum duration should be---. Options & $34(42.0)$ & $26(31.3)$ & $38(43.7)$ & $98(39.0)$ \\
\hline $\begin{array}{l}\text { 5- Hand decontamination: includes washing the--with antiseptic soap for } 30 \text { seconds. } \\
\text { Options }\end{array}$ & $34(42.0)$ & $35(42.2)$ & $38(43.7)$ & 107(42.6) \\
\hline 6- Alcohol hand rub substitutes hand washing even if the hands are soiled. False & $22(27.2)$ & $29(34.9)$ & $21(24.1)$ & $72(28.7)$ \\
\hline 7- Hand washing is indicated between tasks and procedures on the same patient. True & $33(40.7)$ & $37(44.6)$ & $49(56.3)$ & $119(47.4)$ \\
\hline 8- Use of gloves replaces the need for hand washing. False & $31(38.3)$ & $39(47.0)$ & $41(47.1)$ & $111(44.2)$ \\
\hline 9- Hand washing is indicated after removal of gloves. True & $46(56.8)$ & $46(55.4)$ & $55(63.2)$ & $147(58.6)$ \\
\hline 10- Hand washing is needed with patients with respiratory infections. True & $26(32.1)$ & $25(30.1)$ & $35(40.2)$ & $86(34.3)$ \\
\hline Score for hand hygiene (out of 10): Median (mean \pm SD). & $5.5(5.0 \pm 2.1)$ & $6.0(5.3 \pm 2.5)$ & $6.0(6.2 \pm 2.1)$ & $6.0(5.8 \pm 2.2)$ \\
\hline
\end{tabular}

SPs: standard precautions, $\mathrm{IC}=$ infection control.

\subsection{Personal Protective Equipment}

Table 2 shows the correct responses to items related to the domain of Personal Protective Equipment (PPE) by clinical years included. Of the surveyed students $68.1 \%$ identified the role of PPE in complete elimination of the risk of acquiring infections, $74.5 \%$ stated that PPE should be exclusively used by laboratory and cleaning staff, and should be used only in presence of contact with blood (in 61.4\%), 47.8\% believed that gloves and masks should be re-used after proper cleaning. Also, 45.8\% agreed that gloves should be changed between different procedures on the same patient, $43.4 \%$ correctly respond about re-using masks and gloves if dealing with the same patient. The total score for this domain was low (3.8 \pm 1.9 out of 9 points), and there was no statistical difference in relation to year of enrollment at the college. 
Table 2. Correct responses about personal protective equipment by the included medical students by their years at college

\begin{tabular}{|c|c|c|c|c|}
\hline \multirow[b]{2}{*}{ Personal protective equipment } & \multicolumn{4}{|c|}{ Years and Correct answers: No. (\%) } \\
\hline & $\begin{array}{l}\text { Fourth } \\
(\mathrm{N}=\mathbf{8 1})\end{array}$ & $\begin{array}{l}\text { Fifth } \\
(\mathrm{N}=\mathbf{8 3})\end{array}$ & $\begin{array}{l}\text { Sixth } \\
(\mathrm{N}=87)\end{array}$ & $\begin{array}{l}\text { Total } \\
(\mathrm{N}=\mathbf{2 5 1})\end{array}$ \\
\hline $\begin{array}{l}\text { 1- PPE such as masks and head caps provides protective barriers against } \\
\text { infection. True }\end{array}$ & $42(51.9)$ & $45(54.2)$ & $49(56.3)$ & $136(54.2)$ \\
\hline 2- Use of PPE eliminates risk of acquiring occupational infections. True & $25(30.9)$ & $25(30.1)$ & $30(34.5)$ & $80(31.9)$ \\
\hline $\begin{array}{l}\text { 3- PPE is exclusively suitable to laboratory and cleaning staff for their } \\
\text { protection. False }\end{array}$ & $17(21.0)$ & $20(24.1)$ & $27(31.0)$ & $64(25.5)$ \\
\hline 4- PPE should be used only whenever there is contact with blood. False & $24(29.6)$ & $31(37.3)$ & $42(48.3)$ & $97(38.6)$ \\
\hline 5- Gloves and masks can be re-used after proper cleaning. False & $34(42.0)$ & $46(55.4)$ & $51(58.6)$ & $131(52.2)$ \\
\hline $\begin{array}{l}\text { 6- Used PPE are to be discarded through regular municipal disposal } \\
\text { systems. False }\end{array}$ & $24(29.6)$ & $25(30.1)$ & $21(24.1)$ & $70(27.9)$ \\
\hline $\begin{array}{l}\text { 7- Gloves should be changed between different procedures on the same } \\
\text { patient. True }\end{array}$ & $32(39.5)$ & $38(45.8)$ & $45(51.7)$ & $115(45.8)$ \\
\hline 8- Masks made of cotton or gauze are most protective. False & $14(17.3)$ & $27(32.5)$ & $25(28.7)$ & $66(26.3)$ \\
\hline 9- Masks and gloves can be re-used if dealing with same patient. False & $25(30.9)$ & $30(36.1)$ & $54(62.1)$ & $109(43.4)$ \\
\hline Score for personal protective equipment: Median $($ mean \pm SD) & $3.5(3.2 \pm 1.5)$ & $4.0(3.7 \pm 2.2)$ & $4.0(4.2 \pm 2.0)$ & 4.0(3.8 \pm 1.9$)$ \\
\hline
\end{tabular}

PPE: Personal Protective Equipment.

\subsection{Sharp Disposal, Sharp Injuries and Care of Health Providers}

Table 3 depicts the correct responses towards sharp disposal and sharp injuries and care of the health care providers. Only $17.9 \%$ and $32.7 \%$ respectively correctly responded to the false statements that used needles should be recapped or bent after use, more than $90 \%$ of the participants failed to identify the label of the container for sharp disposal. Also, $23.1 \%$ of the students correctly answered that post exposure prophylaxis is used in managing accidental sharp injuries from an HIV-infected patient and $22.7 \%$ correctly stated that the immediate management of sharp injuries including washing in running water and soap. The total score of this domain was $2.8 \pm 1.9$ (out of 8 points). Those of $6_{\text {th }}$ years have significantly higher scores compared to $4_{\text {th }}$ and $5_{\text {th }}$ years $(\mathrm{P}=0.008)$. Care of health care providers showed that students' responses reflecting their lack of knowledge, more than $75 \%$ failed to identify the required vaccinations for health care providers, only $21.1 \%$ of students correctly identified the size of risk following the exposure to needle stick injuries from an HIV/AIDS patient. The total score of this domain was $3.8 \pm 2.0$ (out of 9 points), significantly more among $6_{\text {th }}$ year and higher among males (Figure 1). 
Table 3. Correct responses of medical students about sharp injuries/disposal and health of health care providers by years of study

\begin{tabular}{|c|c|c|c|c|}
\hline \multirow[b]{2}{*}{ Sharps disposal and sharp injuries } & \multicolumn{4}{|c|}{ Years and Correct answers: No. (\%) } \\
\hline & $\begin{array}{l}\text { Fourth } \\
(\mathrm{N}=\mathbf{8 1})\end{array}$ & $\begin{array}{l}\text { Fifth } \\
(\mathrm{N}=\mathbf{8 3})\end{array}$ & $\begin{array}{l}\text { Sixth } \\
(\mathbf{N}=87)\end{array}$ & $\begin{array}{l}\text { Total } \\
(\mathrm{N}=\mathbf{2 5 1})\end{array}$ \\
\hline 1- Used needles should be recapped after use to prevent injuries. False & $9(11.1)$ & $16(19.3)$ & $20(23.0)$ & $45(17.9)$ \\
\hline 2- Used needles should be bent after use to prevent injuries. False & $18(22.2)$ & $28(33.7)$ & $36(41.4)$ & $82(32.7)$ \\
\hline 3- Sharps container is labeled with ....: Options & $3(3.7)$ & $8(9.6)$ & $7(8.0)$ & $18(7.2)$ \\
\hline 4- Soiled sharps objects should be shredded before final disposal. True & $16(19.8)$ & $19(22.9)$ & $21(24.1)$ & $56(22.3)$ \\
\hline 5- Sharps injuries should be managed with no need of reporting. False & $22(27.2)$ & $27(32.5)$ & $31(35.6)$ & $80(31.9)$ \\
\hline 6- Needle-stick injuries are the least commonly encountered in general practice. False & $30(37.0)$ & $31(37.3)$ & $42(48.3)$ & $103(41.0)$ \\
\hline $\begin{array}{l}\text { 7- Post-exposure prophylaxis is used for managing injuries from an HIV-infected patient. } \\
\text { True }\end{array}$ & $16(19.8)$ & $17(20.5)$ & $25(28.7)$ & $58(23.1)$ \\
\hline 8- Immediate management of sharps injuries includes: Options & $14(17.3)$ & $23(27.7)$ & $20(23.0)$ & $57(22.7)$ \\
\hline Score for sharps disposal and injuries: Median (mean \pm SD). & 3.0(2.7 \pm 1.5$)$ & $3.0(2.6 \pm 2.0)$ & 3.0(3.4 \pm 1.9$)$ & $3.0(2.8 \pm 1.9)$ \\
\hline \multicolumn{5}{|l|}{ Care of healthcare providers: } \\
\hline $\begin{array}{l}\text { 1- Immunization history of health care providers should be obtained before recruitment. } \\
\text { True }\end{array}$ & $37(45.7)$ & $46(55.4)$ & $56(64.4)$ & $139(55.4)$ \\
\hline 2- Routine immunizations for healthcare providers include HIV, rubella and rabies. False & $15(18.5)$ & $20(24.1)$ & $27(31.0)$ & $62(24.7)$ \\
\hline 3- Healthcare providers should receive annual influenza vaccine. True & $29(35.8)$ & $32(38.6)$ & $45(51.7)$ & $106(42.2)$ \\
\hline 4- Healthcare providers should be tested annually by tuberculin skin test. True & 24(29.6) & 23(27.7) & $32(36.8)$ & $79(31.5)$ \\
\hline $\begin{array}{l}\text { 5- The risk for a health provider to acquire HIV infection after needle-stick injury is: } \\
\text { Options }\end{array}$ & $16(19.8)$ & $17(20.5)$ & $20(23.0)$ & $53(21.1)$ \\
\hline $\begin{array}{l}\text { 6- Post exposure immunization prevents the risk of hepatitis B infection following } \\
\text { exposure. True }\end{array}$ & $32(39.5)$ & $28(33.7)$ & $48(55.2)$ & $108(43.0)$ \\
\hline $\begin{array}{l}\text { 7- For the prevention of hepatitis B, immunizations are recommended for all healthcare } \\
\text { workers. True }\end{array}$ & $52(64.2)$ & $51(61.4)$ & $55(63.2)$ & $158(62.9)$ \\
\hline $\begin{array}{l}\text { 8- Following exposure to a patient with flu, antibiotics are required for prevention of } \\
\text { infection. False }\end{array}$ & $12(14.8)$ & $18(21.7)$ & $22(25.3)$ & $52(20.7)$ \\
\hline $\begin{array}{l}\text { 9- Health providers with highest risk of exposure to tuberculosis include radiologists. } \\
\text { True }\end{array}$ & $16(19.8)$ & $25(30.1)$ & $31(35.6)$ & $72(28.7)$ \\
\hline Score for care of the healthcare workers: Median (mean \pm SD). & $4.0(4.0 \pm 1.5)$ & $3.0(3.1 \pm 2.2)$ & $5.0(4.3 \pm 2.3)$ & $4.0(3.8 \pm 2.0)$ \\
\hline
\end{tabular}




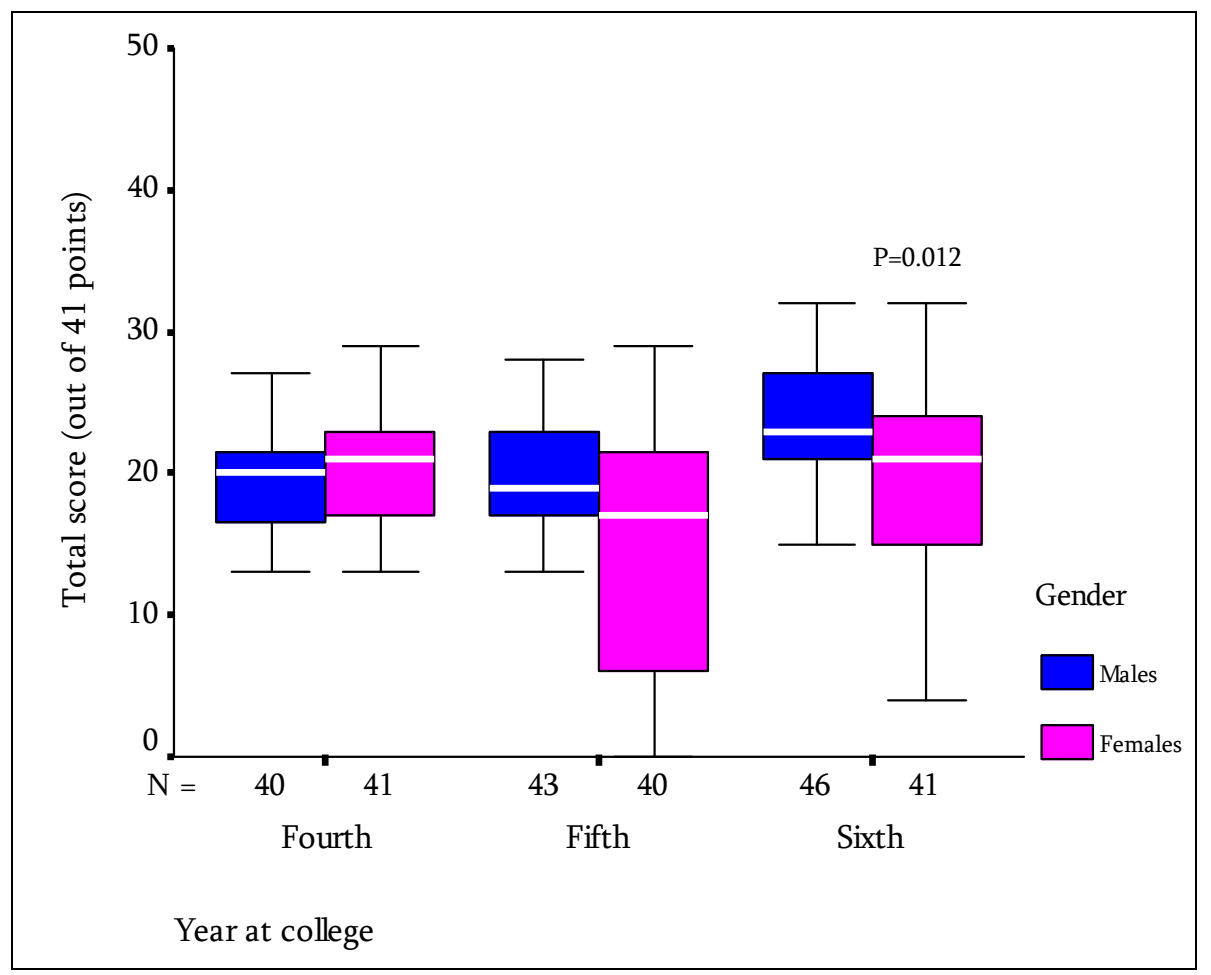

Figure 1. Total knowledge scores of the included medical students about standard precautions in relation to genders and year at college, King Faisal University

\subsection{The Acceptable Level of Knowledge and Its Correlates}

We have set the cutoff for being knowledgeable towards infection control and SPs with scores that $\geq$ the $75^{\text {th }}$ percentile ( $\geq 24$ out of a total of 41 points), of the total, $67(26.7 \%)$ students scored $\geq 24,18 / 81(22.2)$ in $4^{\text {th }}$ year, $17 / 83(20.5 \%)$ in $5^{\text {th }}$ year and $32 / 87(36.8 \%)$ in $6^{\text {th }}$ year, $37 / 129(28.7 \%)$ among males and $30 / 122(24.6 \%)$ among females $(\mathrm{P}=0.463)$. Table 4 depicts the results of binary logistic regression analysis, knowledge score was significantly positively correlated with the year at the college and significantly negatively associated with non receiving of teaching/educational training materials, while gender, receiving of previous training/orientation towards infection control and SPs and attitude score had no significant association with the knowledge scores.

Table 4. Logistic regression model for the possible correlates of higher knowledge toward standard precautions among the included medical students

\begin{tabular}{|c|c|c|c|c|c|}
\hline Independent variables & B & S.E. & P value & Odds ratio & $\begin{array}{l}\text { 95\% Confidence } \\
\text { intervals }\end{array}$ \\
\hline Gender (female) & -.471 & .305 & 0.123 & 0.62 & $(0.34-1.14)$ \\
\hline Year at the college & .415 & .195 & 0.034 & 1.51 & $(1.03-2.22)$ \\
\hline Previous training on infection control/SP (no) & -.499 & .493 & 0.310 & 0.61 & $(0.23-1.60)$ \\
\hline Received educational materials/instructions on IC/SP (no) & -.682 & .330 & 0.039 & 0.51 & $(0.27-0.97)$ \\
\hline Attitude scores & .070 & .061 & 0.251 & 1.072 & $(0.95-1.21)$ \\
\hline
\end{tabular}

$\mathrm{B}=$ régression coefficient, $\mathrm{S} . \mathrm{E}=$ standard error.

Percent predicted $=71.4$, Hosmer and Lemeshow Chi square for the model $=8.65, \mathrm{P}=0.061$.

\subsection{Sources of Students' Knowledge}

Figure 2 shows the main sources of medical students' information in relation to the different domains of infection control and SPs. With the exception of the general concept and health care of health providers' domains, the current curriculum was not cited as the main source of their knowledge especially for the PPE and sharps management domains. 


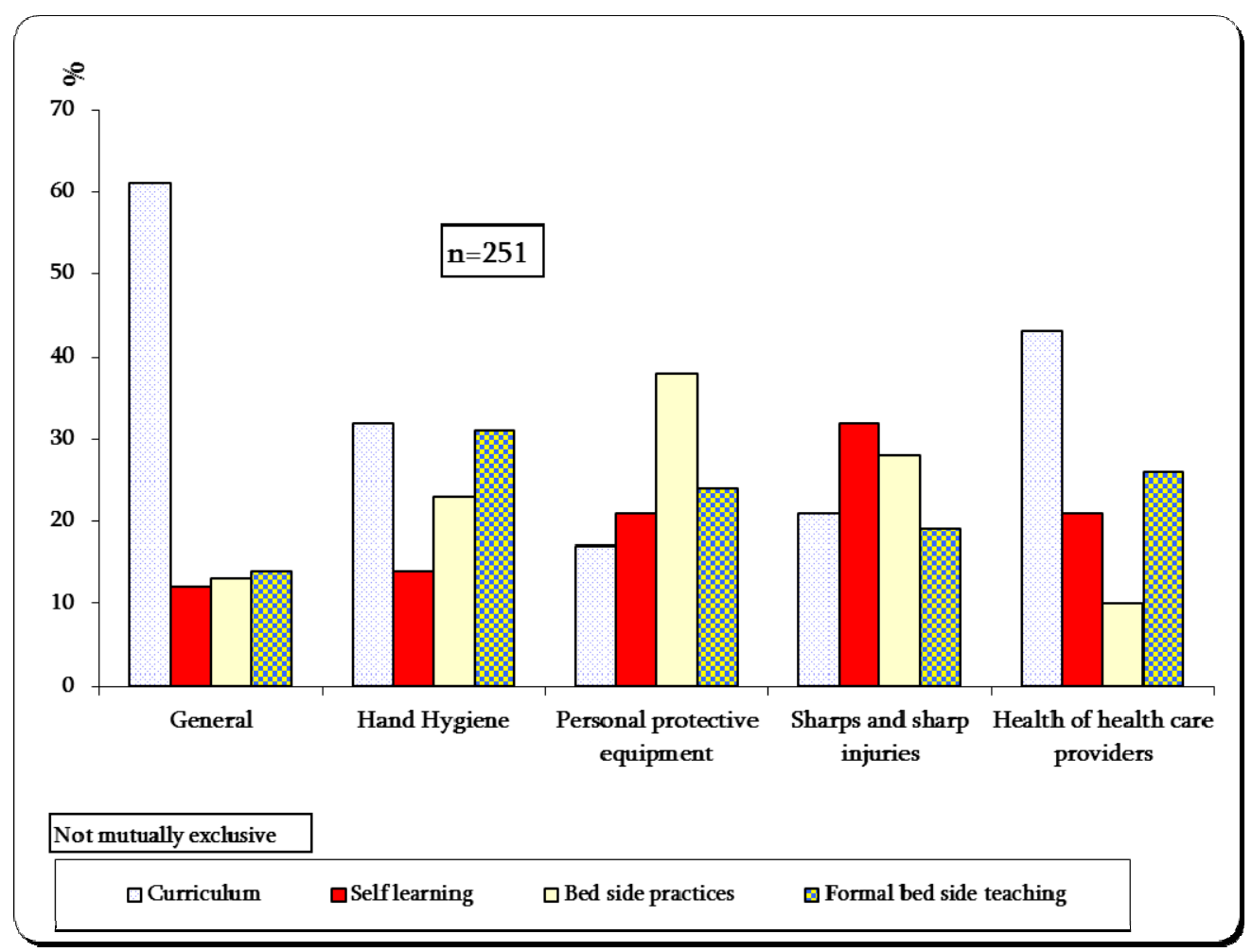

Figure 2. The main sources for information about the different domains of infection control and standard precautions among the surveyed medical students at King Faisal University

\subsection{Attitudes toward the Received Training/Teaching of Infection Control and SPS}

Table 5 depicts the attitudes of medical students towards their satisfaction with the current curricular content and the received training towards infection control and SPs. Of the included students $61.4 \%$ disagreed and strongly disagreed that the current curriculum provides them with enough information on infection control and SPs, $69.9 \%$ disagreed and strongly disagreed about the availability of extracurricular training and/or orientation sessions towards infection control and SPs at the college, $60.1 \%$ disagreed and strongly disagreed about the role of their tutors and faculty in providing them with necessary information on how to avoid health facilities related infections before their entrance into clinical training at hospitals, and almost $80 \%$ of the included students agreed or strongly agreed about their need to receive training and orientations towards infection control and SPs. The attitude score showed a total of $9.6 \pm 2.7$ (median of 9.0 out of 15 points), $4^{\text {th }}$ year attitude score was the least $(8.5 \pm 2.6$, compared to $9.3 \pm 2.2,11.0 \pm 2.7$ for the $5^{\text {th }}$ and $6^{\text {th }}$ years respectively (Kruskall Wallis, $\mathrm{P}=0.001$ ).

Table 5. Attitudes of the included medical students towards current curricular sufficiency and their training needs for infection control and standard precautions

\begin{tabular}{llllll}
\hline \multicolumn{2}{l}{ Responses: No. (\%) } & & & & \multicolumn{2}{l}{ Statements } \\
\hline Strongly disagree & Disagree & Neutral & Agree & Strongly agree & \\
\hline $68(27.1)$ & $86(34.3)$ & $41(16.3)$ & $40(15.9)$ & $16(6.4)$ & $\begin{array}{l}\text { 1- Current curriculum provides enough information on IC and SPs. } \\
99(39.4)\end{array}$ \\
$74(29.5)$ & $39(15.5)$ & $24(9.6)$ & $15(6.0)$ & $\begin{array}{l}\text { 2- Training/orientation sessions about IC and SPs are provided to } \\
\text { medical students. }\end{array}$ \\
$101(40.2)$ & $50(19.9)$ & $58(23.1)$ & $31(12.3)$ & $11(4.4)$ & $\begin{array}{l}\text { 3-Tutors and faculty provided us with enough information on how to } \\
\text { avoid health facilities related- infections before clinical rotations. }\end{array}$ \\
$94(37.5)$ & $77(30.7)$ & $43(17.1)$ & $19(7.6)$ & $18(7.2)$ & $\begin{array}{l}\text { 4- I received hands on training on how to avoid health } \\
\text { facilities-related infections using case scenarios and simulations. }\end{array}$ \\
$5(2.0)$ & $6(2.4)$ & $40(15.9)$ & $111(44.2)$ & $89(35.5)$ & 5- I need to receive training on IC and SPs. \\
\hline
\end{tabular}

$\mathrm{IC}=$ infection control, $\mathrm{SPs}=$ standard precautions 


\section{Discussion}

In this study the total score for knowledge was $19.3 \pm 9.1$ (out of 41 points) with a total of 67 students (26.7\%) scored $\geq 24$ which is considered to be acceptable, students' knowledge differed according to the specific areas, the highest scores was noticed along the domain of hand hygiene, and care of the health care providers, while sharp management and injuries and PPE showed the least scores. Tavolacci et al. (2008) reported in their study that the highest scores were achieved for knowledge of standard precautions and hand hygiene, and the worst score was for knowledge of nosocomial infection. Knowledge of hand hygiene should be improved, because it is the most effective measure for interrupting the transmission of microorganisms that cause nosocomial infection (Tavolacci et al., 2008), interventions are needed to increase the knowledge in the domains of sharp management and injuries and PPE among our students.

Also, in this study, $18.3 \%$ and $51 \%$ did not recognize the goal of infection control and the precise definition of SPs respectively, and only $41.8 \%$ recognized that all patients irrespective of their diagnoses are sources of infection. These findings are consistent with the results of Amin \& Al Wehedy (2009) who found a similar pattern among primary care providers in Al Hassa, Saudi Arabia.

For hand hygiene, only $39.0 \%$ were able to respond correctly about the standard duration of hand washing, $51.1 \%$ believed that alcohol hand rub can replace hand washing even if the hands were soiled, $33.5 \%$ incorrectly acknowledged that using gloves replaces the need for hand washing and only $34.3 \%$ correctly stated the need for hand washing in dealing with patients with respiratory infections. Students in this domain demonstrated an acceptable level of knowledge as $156(62.2 \%)$ scored 6 or more points (out of 10). These results are compatible with findings reported from different colleges in the Middle East and Western countries (Askarian et al., 2004; Barikani, 2012; Tavolacci et al., 2008; Mann \& Wood 2006; Koeing \& Chu, 1993; Kim et al., 2001).

Askarian et al. (2004) have found that despite of the acceptable knowledge of medical students, there was poor compliance especially in hand hygiene, others added that while it seems rational that knowledge and attitude should have an impact on practice, no change will be observed if it is not possible to comply with existing recommendations, and the found disparity between knowledge and practice could also be due to the unavailability of protective barriers, inadequate equipment, carelessness, malpractice of senior colleagues or interference of devices with working skills (Kim et al., 2001).

The results of this study endorsed the need for curricular changes as recommended by similar study among medical students in Qassim Medical school, Saudi Arabia to assess their knowledge and compliance with hand hygiene, where it was found that only $29 \%$ of students were able to identify all the five indications related to hand hygiene, with overall hand hygiene compliance of only $17 \%$ (al-Kadi \& Salatai, 2012). Lack of hand hygiene awareness and compliance in medical students has been attributed to many factors. The most important is the lack of role model; the behavior of students is strongly influenced and molded by their mentor's attitude at the bed side. This has been validated in reference to hand hygiene practices in multiple studies (Mann \& Wood, 2006; Koeing \& Chu, 1993). The role models change with each passing year of training from teachers to senior colleagues and if any of these role models are performing faulty hand hygiene, as is very common in hospital settings, and then the students are likely to be less compliant (al-Kadi \& Salati, 2012).

The current study revealed that many misconceptions related to the PPE indications, uses, and their role in preventing nosocomial infections are present. This domain showed the least level of knowledge with several misconceptions. The included students showed a much lower score than those reported from Western similar studies where it was found that for instance $65 \%$ of medical students gave the correct answers about the use of gloves (Jeffe et al., 1998). Further, this study also showed that only $17.9 \%$ and $32.7 \%$ respectively provided correct responses about pending and recapping of the used needles, only $23.1 \%$ of the students correctly mentioned the role of post exposure prophylaxis in managing sharp injuries from an HIV-infected patient and $22.7 \%$ correctly stated that the immediate management of sharp injuries includes washing in running water and soap. Similar results were found among health care providers ( $\mathrm{HCPs}$ ) at the primary level of care in Saudi Arabia (Amin \& $\mathrm{Al}$ Wehedy, 2009).

Kim et al. (2001) reported that knowledge of SPs especially in the domain of sharp injuries was better among nursing students than among medical students. Nurses are a subgroup of HCPs at high risk for needle stick injuries because they are frequently involved with invasive procedures. However, it could be expected that the knowledge level about infection control and SPs would be similar regardless of curriculum. Medical students have just as high a risk of needle stick injuries as do nursing students, because of their limited clinical experience, (Feather et al., 2000; Monsalve et al., 2007; Smith \& Leggat, 2006) and they should observe the same precautions during patient care to avoid cross-transmission and to prevent spread of nosocomial infection. 
In this study, only $26.7 \%$ of the surveyed students were found to have an acceptable level of knowledge. The previous notion implying that students who are lacking the proper knowledge and if this is coupled with presence of misconceptions especially related to hand hygiene, sharp management and PPE, this combination will make them more vulnerable to health care facilities - related infections. These results are consistent with those reported from other medical schools in the Middle East where the overall knowledge for SPs is poor (Askarian et al., 2004; al-Kadi \& Salati, 2012).

In this study, self learning and informal bed side clinical practices were the main sources for knowledge as cited by many students especially in domains of sharp injuries, PPE and care of health care providers, these results are inconsistent with studies carried out in more developed countries where teaching during the curriculum was the main source of information, and the information about SPs was emphasized more during the curriculum for nursing students than for the medial students (Tavolacci et al., 2008).

In addition, the study also demonstrated the attitudes of medial students regarding the current teaching and curricular contents for infection control and SPs with substantial perception that the current curriculum, the received training and orientation at the clinical teaching are insufficient which endorse the fore mentioned findings about the main sources of information among the surveyed students.

Learning practices are indispensable for improving student knowledge of nosocomial infection (Rosethal et al., 1999; Snow et al., 2006) and the prevention of infection transmission (Calabro et al., 1998; Jeffe, 1999; Deisenhammer et al., 2006). In this study, the level of knowledge was significantly correlated with year at college; this can be explained by the fact that those at advanced years are more exposed to clinical practices with substantial exposures to patients, clinical practices and senior clinical staff in hospital wards compared to $4^{\text {th }}$ and $5^{\text {th }}$ years. Teaching infection control to health care students is a challenge both with respect to developing a cohesive program and encouraging students to adopt correct attitudes early in their careers. Kim et al. (2001) showed a positive correlation between knowledge and performance of SPs. Nobile et al. (2002) reported that a positive attitude about hand disinfection was higher among HCPs with a higher level of knowledge. However, educational background is one of the factors influencing compliance with good practices and education works synergistically with other factors namely behavior and practice (Nobile et al., 2002; Pittet, 2004; Helfgott et al., 1998; Jumaa, 2005). In this study previous training on SPs and infection control was not a positive predictor for higher knowledge and this could be referred to nature and contents of these training (limited in time and contents, mostly non specific and without hands on training). Studies showed that specific training of SPs can quickly improve students' knowledge of infection control in a short period of time (Colombo et al., 2002; Nobile et al., 2002; Diekema et al., 1995). Some authors recommended that future educational approaches should include rigorous curricular reform with pragmatic presentation of effective hand hygiene and SPs, feedback from teachers at the bedside, and inclusion of hygiene scores for students in all clinical training courses (Tavolacci et al., 2008; Kim et al., 2001).

\section{Study Limitations}

The study inherent a study design limitation for being a cross-sectional, secondly, observation of students' behaviors, skills and compliance was not possible as the clinical rotations were carried out at facilities not affiliated to the College of Medicine and finally, the possible problem with the questionnaire design as most of the items had the options of true/false which may provide the opportunity for guessing.

\section{Conclusion}

The overall knowledge scores for SPs were low especially in the domains of hand hygiene, sharp management, and personal protective equipment reflecting insufficient and ineffective instructions received by medical students through the current curriculum posing them vulnerable to health facilities related infections. Proper curricular reform and training are required to protect students and their patients.

\section{References}

al Kadi, A., \& Salati, S. A. (2012). Hand Hygiene Practices among Medical Students. Interdisciplinary Perspectives on Infectious Diseases, 2012, 679129.

Amin, T., \& Al Wehedy, A. (2009). Healthcare providers' knowledge of standard precautions at the primary healthcare level in Saudi Arabia. Healthcare Infection, 14(2), 65-72. http://dx.doi.org/10.1071/HI09107

Askarian, M., Honarvr, B., Tabatabaee, H. R., \& Assadian, O. (2004). Knowledge, practice and attitude towards standard isolation precaution in Iranian medical students. $J$ Hosp Infect, 58, 292-296. http://dx.doi.org/10.1016/j.jhin.2004.07.004 
Barikani, A. (2012). Knowledge, Attitude and Practice towards Standard Isolation Precautions among Iranian Medical Students. Global Journal of Health Science, 4, 2. http://dx.doi.org/10.5539/gjhs.v4n2p142

Bryce, E. A., Scharf, S., Walker, M., \& Walsh, A. (2007). The infection control audit: the standardized audit as a tool for change. Am J Infect Control, 35, 271-283. http://dx.doi.org/10.1016/j.ajic.2006.05.293

Calabro, K., Weltge, A., Parnell, S., Kouzekanani, K., \& Ramirez, E. (1998). Intervention for medical students: effective infection control. Am J Infect Control, 26, 431-436.

Colombo, C., Giger, H., Grote, J., Deplazes, C., Pletscher, W., Lüthi, R., \& Ruef, C. (2002). Impact of teaching interventions on nurse compliance with hand disinfection. $J$ Hosp Infect, 51, 69-72. http://dx.doi.org/10.1053/jhin.2002.1198

Deisenhammer, S., Radon, K., Nowak, D., \& Reichert, J. (2006). Needle stick injuries during medical training. $J$ Hosp Infect, 63, 263-267. http://dx.doi.org/10.1016/j.jhin.2006.01.019

Diekema, D. J., Schuldt, S. S., Albanese, M. A., \& Doevveling, B. N. (1995). Universal precaution training of preclinical students: impact on knowledge, attitudes and compliance. Prev Med, 24, 580-585.

Easton, P. M., Sarma, A., Williams, F. L. R., Marwick, C. A., Phillips, G., \& Nathwani, D. (2007). Infection control and management of MRSA: assessing the knowledge of staff in an acute hospital setting. $J$ Hosp Infect, 66 , 29-33. http://dx.doi.org/10.1016/j.jhin.2006.12.016

Elliott, S. K. F., Keeton, A., \& Holt, A. (2005). Medical students' knowledge of sharps injuries. J Hosp Infect, 60, 374-377. http://dx.doi.org/10.1016/j.jhin.2005.01.033

Feather, A., Stone, S. P., Wessier, A., Boursicot, K. A., \& Pratt, C. (2000). 'Now please wash your hands': the hand washing behavior of final MBBS candidates. $J$ Hosp Infect, 45, 62-64. http://dx.doi.org/10.1053/jhin.1999.0705

Helfgott, A. W., Taylor-Burton, J., Garcini, F. J., Eriksen, N. L., \& Grimes, R. (1998). Compliance with universal precaution: knowledge and behaviour of residents and students in a department of obstetrics and gynecology. Infect Dis Obstet Gynecol, 6, 123-128.

Humphreys, H., \& Richards, J. (2011). Undergraduate and postgraduate medical education on the prevention and control of healthcare-associated infection. More progress is needed. Int $J$ Infect Control, 7, 2. http://dx.doi.org/10.3396/ijic.V7i2.012.11

Hunt, D. C. E., Mohammudaly, A., Stone, S. P. \& Dacre, J. (2005). Hand hygiene behaviour, attitudes and beliefs in first year clinical medical students. $J$ Hosp Infect, 59, 371-373. http://dx.doi.org/10.1016/j.jhin.2004.09.002

Jeffe, D. B., Mutha, S., L'Ecuyer, P. B., Kim, L. E., Singal, R. B., Evanoff, B. A., \& Fraser, V. J. (1997). Healthcare workers' attitudes and compliance with universal precautions: gender, occupation, and specialty differences. Infect Control Hosp Epidemiol, 18, 710-712.

Jeffe, D. B., Mutha, S., Kim, L. E., Evanoff, B. A., L'Ecuyer, P. B., \& Fraser, V. J. (1998). Does clinical experience affect medical students' knowledge, attitudes, and compliance with universal precautions? Infect Control Hosp Epidemiol, 19, 767-771.

Jeffe, D. B., Mutha, S., Kim, L. E., Evanoff, B. A., \& Fraser, V. J. (1999). Evaluation of a preclinical, educational and skills-training program to improve students' use of blood and body fluid precautions: one year follow-up. Preventive Med, 29, 365-373.

Jumaa, P. A. (2005). Hand hygiene: simple and complex. Int $J$ Infect Dis, 9, 3-14. http://dx.doi.org/10.1016/j.jijid.2004.05.005

Kermode, M., Jolley, D., Langham, B., Thomas, M. S., Holmes, W., \& Gifford, S. M. (2005). Compliance with universal/standard precautions among health care workers in rural north India. Am J Infect Control, 33, 27-33. http://dx.doi.org/10.1016/j.ajic.2004.07.014.

Kim, K. M., Kim, M. A., Chung, Y. S., \& Kim, N. C. (2001). Knowledge and performance of the universal precautions by nursing and medical students in Korea. Am J Infect Control, 29, 295-300. http://dx.doi.org/10.1067/mic.2001.114837

Koenig, S., \& Chu, J. (1993). Senior medical students' knowledge of universal precautions. Acad Med, 68, 372-374.

Mann, C. M., \& Wood, A. (2006). How much do medical students know about infection control? J Hosp Infect, 64, 
366-370. http://dx.doi.org/10.1016/j.jhin.2006.06.030

Maqbool, A. (2002). Knowledge, attitude and practices among health care workers on needle-stick injuries. Ann Saudi Med, 22, 396-9.

Monsalve Arteaga, L. C., Martínez Balzano, C. D., \& Carvajal De Carvajal, A. C. (2007). Medical students' knowledge and attitudes towards standard precautions. $J$ Hosp Infect, 65, 371-372. http://dx.doi.org/10.1016/j.jhin.2006.11.009

Nobile, C. G., Montuori, P., Diaco, E., \& Villari, P. (2002). Healthcare personnel and hand decontamination in intensive care units: knowledge, attitudes and behaviour in Italy. J Hosp Infect, 51, 226-232. http://dx.doi.org/10.1053/jhin.2002.1248

Pittet, D. (2004). The Lowbury lecture: behaviour in infection control. J Hosp Infect, 58, 1-13. http://dx.doi.org/10.1016/j.jhin.2004.06.002

Phillips, G. \& Ker, J. (2006). Champion students! Experience with a standardized infection control training package in medical students. $J$ Hosp Infect, 62, 518-519. http://dx.doi.org/10.1016/j.jhin.2005.10.003

Rosenthal, E., Pradier, C., Keita-Perse, O., Altare, J., Dellamonica, P., \& Cassuto, J. P. (1999). Needle stick injuries among French medical students. JAMA, 281(17), 1660.

Sax, H., Perneger, T., Hugonnet, S., Herrault, P., Chraïti, M. N., \& Pittet, D. (2005). Knowledge of standard and isolation precautions in a large teaching hospital. Infect Control Hosp Epidemiol, 26, 298-304. http://dx.doi.org/10.1086/502543

Siegel, J. D., Rhinehart, E., Jackson, M., \& Chiarello, L. (2007). Healthcare Infection Control Practices Advisory Committee. Guideline for isolation precautions: preventing transmission of infectious agents in healthcare settings 2007. Centers for Disease Control (CDC).

Smith, D. R., \& Leggat, P. A. (2005). Needlestick and sharps injuries among nursing students. $J$ Adv Nurs, 51, 449-455. http://dx.doi.org/10.1111/j.1365-2648.2005.03526.x

Snow, M., White, G. L. Jr., Alder, S. C., \& Stanford, J. B. (2006). Mentor's hand hygiene practices influence student's hand hygiene rates. Am J Infect Control, 34, 8-24. http://dx.doi.org/10.1016/j.ajic.2005.05.009

Tavolacci, M. P., Ladner, J., Bailly, L., Merle, V., Pitrou, I., \& Czernichow, P. (2008). Prevention of Nosocomial Infection and Standard Precautions: Knowledge and Source of Information among Healthcare Students. Infection Control and Hospital Epidemiology, 29(7), 642-647. http://dx.doi.org/10.1086/588683

Wiwanitkit, V. (2002). Knowledge survey concerning universal precaution among the Thai preclinic year medical students: a medical school-based study. Am $J$ Infect Control, 30, 255-256. http://dx.doi.org/10.1067/mic.2002.124533 